\title{
Prosodic contours of migrant learners of French
}

Darya Sandryhaila-Groth

UFR Linguistique, LLF, Paris-Diderot Paris 7, France

https://doi.org/10.36505/ExLing-2017/08/0023/000325

\begin{abstract}
This study concerns an aspect of L2 learning: the realization of the prosodic contours of short French sentences read by migrant learners. They are enrolled in an intensive French course at advanced A1 level as defined by the CEFR. The multimedia software WinPitch is used for analyses.
\end{abstract}

Key words: L2 in immersion, prosodic contours, prosodic morphing

\section{Introduction}

In France, according to the national law, immigrants need to learn French in a language school as a part of integration into French culture and daily life. To stay in France and to pursue the professional studies, they have to pass a proficiency exam called "Diplôme Initial de Langue Française" (DILF - Initial French Knowledge Diploma) (Gloaguen-Vernet 2009). This exam is only awarded to foreigners living on French territory. To help the learners improve their oral expression, we worked on the correction of their pronunciation of French sentences, needed to pass DILF oral exam.

\section{Methodology}

For this study, two recordings of learners of French were analyzed: four male and three female young adults, without any prior knowledge of French and with different L1 (Bangla, Portuguese, Albanian and Chinese). They completed three phases: a first and a final recording and a training phase with WinPitch LTL (Language Teaching and Learning) in between.

\section{Hypothesis}

Hypothesis 1: during the first recordings, the learners will do much more chunking while reading, as a lack of syntactic and prosodic knowledge of sentence grouping and a weak knowledge of the French graphic code. Hypothesis 2: during the final recordings, the learners will keep the correct prosodic pattern, because the realtime visualization during the training phase with WinPitch LTL will allow them to achieve a good cohesion of text, including the prosodic pattern, thanks to the matching of the prosodic structure and the syntactic one.

ExLing 2017: Proceedings of 8th Tutorial and Research Workshop on Experimental Linguistics, 19-22 June, Heraklion, Crete, Greece 


\section{Corpus}

Six declarative sentences were recorded and analyzed. The final realization was compared with the model (native French speaker). The model speaker had to read the sentences rather slowly as requested for A1 learners, but emotional variations were still realized.

\section{Intonational model}

According to the intonational model of P. Martin (Martin 1975, 1982, 2015), every prosodic contour has a different movement on stressed syllables depending on the contour of the last word in the sentence. There is a hierarchical order of the syntactic units. The prosodic structure is based on the slope contrast between successive stressed (prominent) syllables. At the first level, rising contours are called $\mathrm{C} 1$ and falling ones $\mathrm{C} 0$. In the inventory of contours, there can be furthermore a $\mathrm{C} 2$ and a $\mathrm{Cn}$. Within a single sentence there is the same amount of intonational contours and accented syntactic units (Lepetit and Martin 1990). According to the phonosyntax principle, the prosodic structure should match the syntactic one. All recorded sentences were annotated following this principle.

\section{An example of a sentence analyzed with WinPitch}

In Figure 1, left panel, the model speaker read: Martine met ses livres et ses cahiers sur la table. "Martine puts her books and her exercise books on the table." There are four prosodic contours, located on stressed vowels, marked in bold in text: $\mathrm{C} 2$ green, $\mathrm{Cn}$ blue, $\mathrm{C} 1$ maroon, and $\mathrm{C} 0$ yellow. In right panel, a male learner realization of the same sentence in the final recording. He realized the same contours and a similar duration as the model.
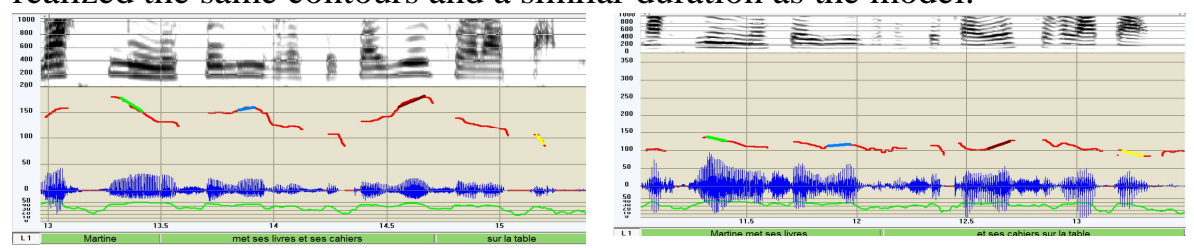

Figure 2. Left: Contours of the model. Right: final recording of a learner.

\section{Results}

Figure 2 summarizes the learner's production of all corpus sentences and their contours. The blue bars represent the realized number of contours for each of the seven learners during the first recording. In this first phase, the learners didn't hear the model yet and read the sentences according to their own understanding. The red bars represent the realized number of contours 
during the final recording. In this last phase, we compared the learners' contours with the model.

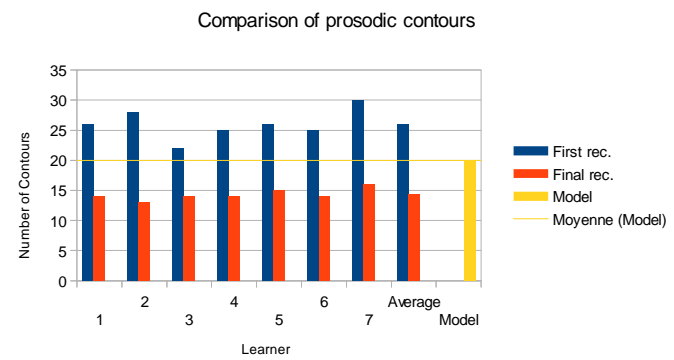

Figure 3. Comparison of prosodic contours between learners' first and final recordings, and the model speaker.

Next in Figure 3, on the y-axis, more detail of the learners contours vs., the model contours are on the $\mathrm{x}$-axis. The learners realized all final falling contour $\mathrm{C} 0$ correctly. The rising contour $\mathrm{C} 1$, the falling contour $\mathrm{C} 2$, and the neutral contour $\mathrm{Cn}$ which can slightly rise or fall or stay at the same melodic level. $\mathrm{Cn}$ was the most problematic contour. I also add a $\mathrm{C}+$ to show that the learners realized a contour, while no one exists in the model. Moreover, a $\varnothing$ sign indicates when the model didn't stress a grammatical word, while the learners stressed the word.

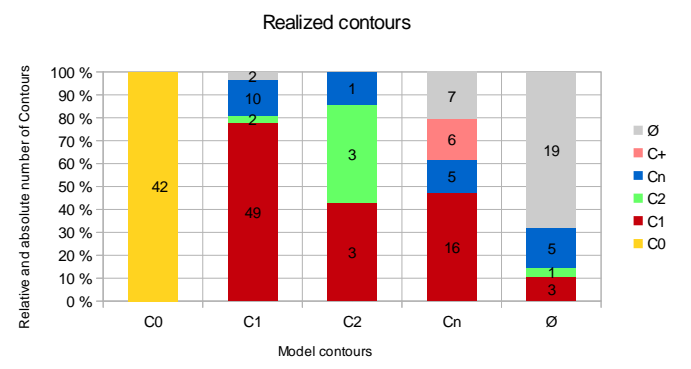

Figure 4. Number of realized contours in final recording. Relative numbers on y-axis, and absolute numbers as inset.

Finally in Figure 4, the comparison of sentences duration is shown. During the first recording, the learners realized a lot of chunking and stressed nearly each word (Guimbretière 1997). The duration of the final recording almost matches with the model duration, while the duration of the first recording is 1.4 times longer on average.

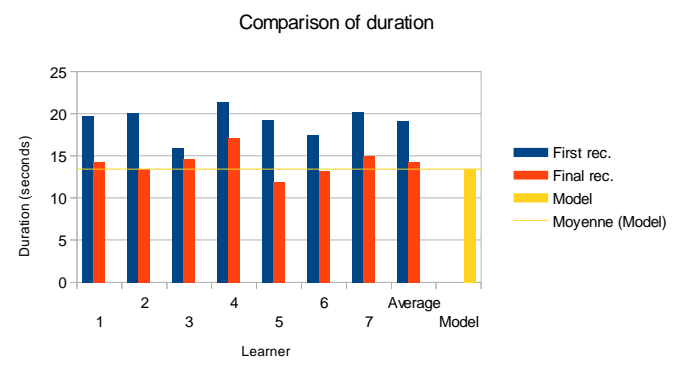

Figure 5.Comparison of sentence duration between first and final recordings. 


\section{Prosodic morphing}

Figure 5 shows an example of prosodic morphing for the initial example given in Figure 1. During the first recording of the sentence, left panel, the learner realized a $\mathrm{C} 1$ rising contour instead of a $\mathrm{C} 2$ falling one. The prosodic morphing was done with the help of WinPitch: F0 modifications are shown in dark green and blue, pauses in yellow, intensity in light blue and duration in purple (right panel). With this manipulation, the learner can hear his own voice producing the right movement. He improved his realization of the contours and the sentence duration was much shorter.
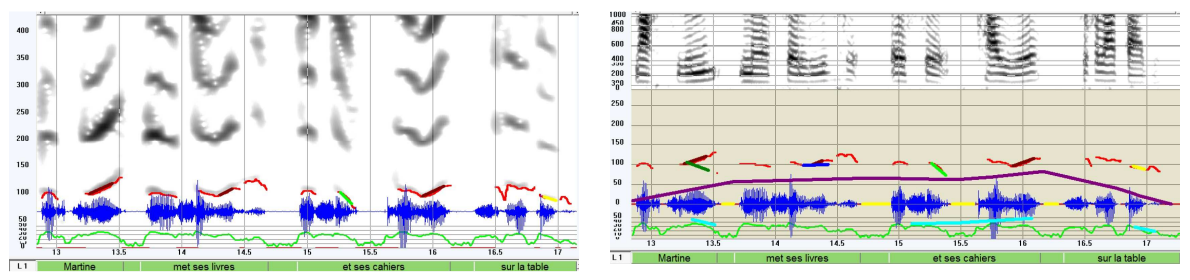

Figure 6. Left: first production of learner. Right: prosodic morphing of the same production.

\section{Conclusions}

The analyses of the first recording show that the first hypothesis is confirmed: the learners produce more chunking while reading unknown sentences. The final recordings support the second hypothesis, that the learners were able to shorten the duration of the sentence and they achieved a better cohesion of text, although some mistakes in the contours remain.

\section{References}

Gloaguen-Vernet, N. 2009. Enseigner le français aux migrants. Paris, Hachette Livre. Gumbretière, E. 1997. Analyse des faits prosodiques dans une perspective d'enseignement/apprentissage. Polyphonie pour I. Fonagy, par J. Perrot, l'Harmattan.

Lepetit, D., Martin, Ph. 1990. Étude différentielle intonative français/anglais. IRAL, vol. XXVIII/2.

Martin, Ph. 2015. The structure of spoken language: intonation in Romance. Cambridge University Press.

Martin, Ph. 1982. Phonetic realizations of prosodic contours in French. Speech Communication I, 283-294.

Martin, Ph. 1975. Analyse phonologique de la phrase française. Linguistics 146, 35 67.

www.winpitch.com 